The test was a page on which all 68 words from the two lists were typed in three columns in random order. After each word appeared the numerals 1 and 2 ,

DOUGLAS L. HINTZMAN, University of Oregon, Eugene, Oreg. 97403, and ROBERT M. WATERS, Pundue University, Lafayette, Ind 47907

List-discrimination performance was tested under six conditions, varying the $I L I$, or interlist interval (immediate vs $15 \mathrm{~min}$ ), and the $T I$, or test interval (immediate vs $15 \mathrm{~min}$ or 1 day). Performance increased with the length of the ILI and decreased with the length of the TI. This outcome lends support to the notion that one factor underlying forgetting is a loss of discrimination of list membership of items in storage, and that this discrimination is based partly on the apparent-recency dimension.

Recently proposed explanations of certain memory phenomena bear a striking resemblance to some principles suggested in 1933 by von Restorff (see Koffka, 1935, pp. 481-493). These explanations have in common the notion that recall performance depends to some extent on the S's ability to discriminate among memory traces in order to assure retrieval of the correct item. Factors that lead to a decrease in the discriminability of traces (called "crowding" by Ceraso, 1967; "loss of differentiation" by Underwood \& Freund, 1968) produce forgetting.

One dimension along which memory traces may be discriminated is recency. Direct studies of recency judgment and discrimination have shown apparent recency to be an approximately logarithmic function of actual recency (Hinrichs \& Buschke, 1968; Yntema \& Trask, 1963). Since, as two nonconcurrent events grow older, their apparent recencies on this scale converge, the resulting loss of discriminability provides an explanation for the fact that proactive interference (PI) increases over time. In accord with this view, it has been demonstrated in both short-term and long-term memory tasks that the longer the time interval between presentations of $A$ and $B$-that is, the greater the difference in apparent recency-the better is later recall of B (Loess \& Waugh, 1967; Underwood \& Freund, 1968).

The present experiment was done to test the notion that PI in long-term memory studies is due to a loss of list discrimination, and that list discrimination, in turn, is at least partly based on apparent recency. The task used was list discrimination or differentiation (Winograd, 1968); the interlist interval was varied (immediate vs $15 \mathrm{~min}$ ) as was the retention interval (immediate, $15 \mathrm{~min}$, and 1 day). List-discrimination performance was expected to be an increasing function of the interlist interval and to decrease with the length of the retention interval.

\section{MATERIALS AND DESIGN}

Stimulus items were 68 three-letter English nouns of greater than 30-per-million frequency (Thorndike \& Lorge, 1944). Each word was typed on white paper with a bulletin typewriter and was photographed, and the negative was mounted in an Easymount slide frame. When projected, the word showed white against a dark background. The 68 words were randomly divided into two lists of 34 words each, to be presented consecutively.

The 2 by 3 factorial design involved two interlist intervals (ILI) and three retention or test intervals (TI). ILIs were: immediate (actually about $30 \mathrm{sec}$ between lists) and $15 \mathrm{~min}$. The TIs were: immediate (about $1 \mathrm{~min}$ between List 2 and test), $15 \mathrm{~min}$, and 1 day. In order to keep Ss occupied during the $15-\mathrm{min}$ intervals, the Edwards Personal Preference Schedule was given as a filler task.

\section{SUBJECTS}

The Ss were 139 introductory psychology students at the University of Texas at Austin, participating as part of a course requirement; the data of four were dropped due to failure to follow instructions. The Ss were run in six groups of 20-25 each, representing the six experimental conditions. Ss signed for the conditions they found most convenient, and no attempt at random assignment was made.

\section{PROCEDURE}

Each group was assembled in a darkened classroom, where they were told that they would be presented with two lists of words, and that they were to remember as many of the words as they could. They were not told at the outset that they would be asked to discriminate list membership. The $E$ then announced the beginning of List 1. The words were presented individually at a 3-sec rate by means of a Kodak Carousel projector paced by a timer. When presentation was completed, E announced the end of List 1 . To the immediate ILI groups, E next announced the beginning of List 2; the 15-min ILI groups were given the filler task for $15 \mathrm{~min}$ and were then presented with List 2 . At the conclusion of List 2 , the immediate TI groups were tested, the 15-min TI groups were given the filler task followed by the test, and the 1-day groups were dismissed with instructions to return the next day, at which time the test was given. followed by a blank line. Ss were instructed to circle the number corresponding to the list in which they thought the word had occurred and then to rate how confident they were in the choice by writing a number in the blank corresponding to a position on a 5-point rating scale. The scale, ranging from 0 (labeled "pure guess") to 4 ("absolutely certain"), appeared at the top of the page for reference by the $S$.

\section{RESULTS AND DISCUSSION}

The numbers of correct list identifications on List 1 and List 2 were tallied for each $S$, and these values were submitted to an analysis of variance. The overall effect of ILI did not reach significance $[F(1,129)=3.80, p>.05]$. The effect of $T I$ was significant $[F(2,129)=15.88, p<.001]$ as was the ILI by TI interaction $[F(2,129)=3.33$, $p<.05]$. This interaction was due to the convergence of the two ILI curves over the retention interval, since a $t$ test for the ILI difference at the 1-day test interval was not significant. Within Ss, only the difference between lists was significant $[F(1,129)=10.54, p<.01]$, indicating a tendency to identify List 2 words correctly slightly more often than List 1 words. This effect appears to reflect a general bias to choose List 2, and it did not interact significantly with any of the between-group factors. The proportion of correct list identifications in the six conditions is presented in Table 1 .

The confidence-rating data are presented in the form of ROC curves in Figs. 1 and 2. These are Type I curves, constructed from a 10-point rating scale, the endpoints of which are "List 1 , Confidence 4 " and "List 2, Confidence 4." It can be seen that performance tended to be better with the longer (15-min) ILI, that it decreased with the length of the TI, and that this decrease was greater for the longer than for the shorter ILI. An unbiased index of discrimination performance for each ROC curve is the $d_{s}$ value, representing the point at which the curve crosses the negative diagonal (Pollack, 1959), and the $d_{s}$ values obtained in each of the six conditions are presented in Table 2.

Table 1

Proportion Correct List Identifications, as a Function of ILI and TI

\begin{tabular}{cccc}
\hline $\begin{array}{c}\text { Inter- } \\
\text { List } \\
\text { Interval }\end{array}$ & \multicolumn{3}{c}{ Test Interval } \\
\cline { 2 - 4 } & $I$ & 15 & $D$ \\
\hline$I$ & .614 & .612 & .564 \\
15 & .698 & .641 & .535 \\
\hline
\end{tabular}




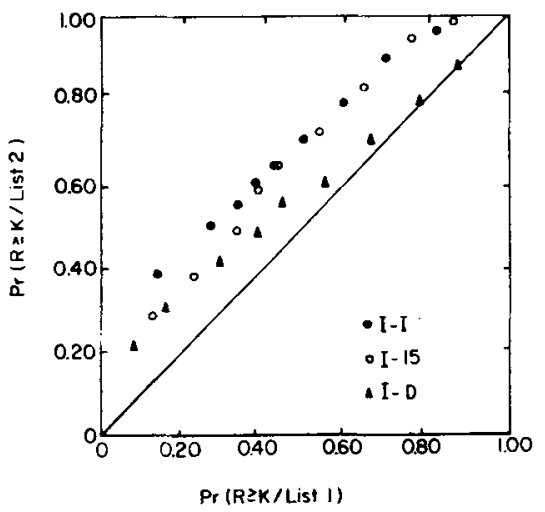

Fig. 1. ROC curres for the immediate ILI conditions $(I=$ immediate; $15=15 \mathrm{~min} ; D=1$; day test intervals).

The present findings show that lengthening the ILI produces a short-term increase in S's ability to discriminate list membership. Presumably, this happens because $S$ bases list discrimination, at least in part, on apparent recency, so that lists differing most in recency are most easily discriminated. As the retention interval grows longer, however, and as memories for both lists grow older, the apparent recencies converge, and the initial advantage produced by the longer ILI eventually disappears. This is the result that was expected on the basis of what is known about recency discrimination (Hinrichs \& Buschke, 1968; Yntema \& Trask, 1963). It provides strong support for the current theoretical accounts of forgetting (especially PI) as being due to a loss of discrimination in memory of list membership-or, in the case of short-term memory tasks, of temporal position-of the to-be-remembered items.

\section{REFERENCES}

CERASO, J. The interference theory of forgetting. Scientific American, 1967, 217, 117-124.

HINRICHS, J. V., \& BUSCHKE, H. Judgment of recency under steady-state conditions. Journal of Experimental Psychology, 1968, 78, 574-579.

KOFFKA, K. Principles of Gestalt psychology. New York: Harcourt, Brace \& World, 1935.

LOESS, H., \& WAUGH, N. C. Short-term memory and intertrial interval. Joumal of Verbal Learning \& Verbal Behavior, 1967, 6, 455-460.

POLLACK, I. Identification of elementary auditory displays and the method of recognition memory. Journal of the Acoustical Society of America, 1959, 31, 1126-1128.

Table 2

ds Values for List Discrimination as a Function of ILI and TI

\begin{tabular}{llcl}
\hline $\begin{array}{c}\text { Inter- } \\
\text { List } \\
\text { Interval }\end{array}$ & \multicolumn{3}{c}{ Test Interval } \\
\cline { 2 - 4 } & I & 15 & D \\
\hline I & .57 & .51 & .33 \\
15 & 1.05 & .72 & .18 \\
\hline
\end{tabular}

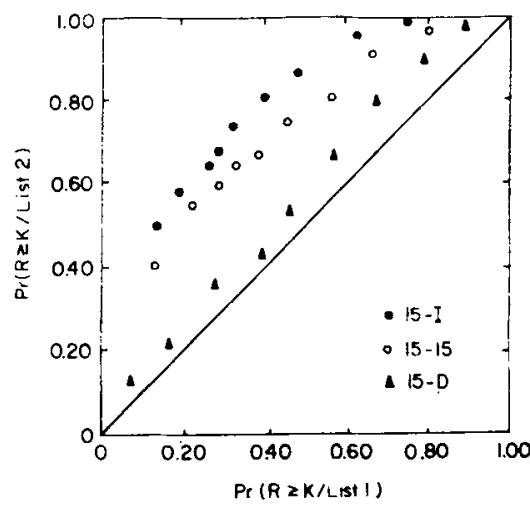

Fig. 2. ROC curves for the 15-min ILI conditions.
THORNDIKE, E. L., \& LORGE, I. The teacher's wond book of 30,000 words New York: Bureau of Publications, Teachers College, Columbia University, 1944.

UNDERWOOD, B. J., \& FREUND, J. S. Effect of temporal separation of two tasks on proactive inhibition. Joumal of Experimental Psychology, 1968, 78, 50-54.

WINOGRAD, E. List differentiation as a function of frequency and retention interval. Joumal of Experimental Psychology, 1968, 76(2, Part 2). YNTEMA, D. B., TRASK, F. P. Recall as a search process. Joumal of Verbal Learning \& Verbal Behavior, 1963, 2, 65-74. NOTE

1. Supported in part by United States Office of Education, National Defense Education Act Title IV Graduate Fellowship Program, Con tract 40-53-0930, and the Advanced Research Projects Agency of the Department of Defense, monitored by the Air Force Office of Scientific Research, Contract F44620-67-C-0099.

\section{Generalization in short-term recognition of}

\section{auditory verbal stimuli}

BARBARA W.s. POTEAT and RICHARD A. KASSCHAU, University of South Carolina, Columbia, S.C. 29208

Groups of second-, fourth-, and sixth-grade school children were asked to indicate whether or not each of 81 words being presented aurally had been presented previously. Using this short-term recognition task, verbal generalization to words related antonymically, synonymically, and phonetographically to the critical repeated word was demonstrated. Generalization was greatest for phonetographically related words.

Many different experimental findings have been subsumed under the terms "semantic conditioning," "semantic generalization," and "mediated generalization." Feather (1965) reviewed 25 studies in this area with a variety of conditioned responses and concluded that, although 22 reported evidence for semantic generalization, only 13 of those had included controls for pseudoconditioning and had differentiated extinction effects from generaljzation effects, and none had controls for simultaneous conditioning to the generalization stimuli.

In view of these difficulties, it is not surprising that a variety of somewhat contradictory results have been reported with respect to the dimensions of generalization. An early experiment by Riess (1946), using GSR, found developmental changes in generalization gradients. His youngest Ss (mean age: 7.75 years) exhibited a gradient along the dimension (from greatest generalization to least): homophones, antonyms, synonyms; those Ss of mean age 10.67: antonym. homophones, synonyms; and the two older groups (mean ages 14.00 and 18.50): synonyms, antonyms, homophones. Korn (1966), using GSR, reported no differences in magnitude of generalization across the same three categories in adult Ss. Similarly, Lemer (1968), using salivation, obtained generalization with both synonyms and antonyms, again without differences, although this was based on only one $S$.

The Ss' task in the present study was designed to reduce or to avoid some of the problems inherent in the classical-conditioning paradigm (e.g., pseudoconditioning and sensitization), to allow group administration, and to test for generalization without specifically training prior responses. The Ss were asked simply to indicate recognition of a word as being repeated in a list being read to them at the time. Generalization was defined as responding in error to words related semantically (antonyms or synonyms) or phonetographically to the repeated stimulus word. The questions dealt with were: (1) Can verbal generalization be demonstrated using a short-term recognition task? (2) If it can, does the response occur to words related phonetographically or semantically to the stimulus word? (3) Finally, can differences be demonstrated as a function of age within elementary-school children? SUBJECTS

Elementary-school children from the second (15 females, 10 males), fourth (12 females, 10 males), and sixth ( 7 females, 13 males) grades of A.C. Moore School, Columbia, South Carolina, participated in the study.

MATERIALS AND PROCEDURE

The stimulus list consisted of 81 English 